\title{
BMJ Open Which aspects of neighbourhood environment are most associated with meeting physical activity recommendations in American adults: an NHIS study
}

Sarah C Gebauer (D) , ${ }^{1}$ Joanne Salas, ${ }^{1}$ Jeffrey Scherrer, ${ }^{1}$ Leigh F Callahan ${ }^{2}$

To cite: Gebauer SC, Salas J, Scherrer J, et al. Which aspects of neighbourhood environment are most associated with meeting physical activity recommendations in American adults: an NHIS study. BMJ Open 2020;10:e038473. doi:10.1136/ bmjopen-2020-038473

- Prepublication history and additional material for this paper are available online. To view these files, please visit the journal online (http://dx.doi. org/10.1136/bmjopen-2020038473).

Received 11 March 2020 Revised 06 August 2020 Accepted 03 September 2020

Check for updates

(C) Author(s) (or their employer(s)) 2020. Re-use permitted under CC BY-NC. No commercial re-use. See rights and permissions. Published by BMJ.

${ }^{1}$ Department of Family and Community Medicine, Saint Louis University School of Medicine, Saint Louis, Missouri, USA

${ }^{2}$ Departments of Medicine and Social Medicine, University of North Carolina at Chapel Hill, Chapel Hill, North Carolina, USA

Correspondence to

Dr Sarah C Gebauer;

sarah.gebauer@health.slu.edu

\section{ABSTRACT}

Objectives To investigate which perceived neighbourhood characteristics are most strongly linked with adequate physical activity (PA) in a nationally representative sample of adults in the USA.

Design Cross-sectional.

Setting USA via 2015 National Health Interview Survey Data.

Participants A group of 28697 non-institutionalised adults with complete data.

Primary outcome measures Meeting PA was defined as $150 \mathrm{~min} /$ week of moderate to vigorous activity.

Results The population had a mean age of $49.6( \pm 18.3)$ years and was $51.3 \%$ female and $66.2 \%$ non-Hispanic white. In adjusted, weighted analysis, places to walk and relax was mostly strongly associated with meeting PA recommendations $(\mathrm{OR}=1.40(95 \% \mathrm{Cl} 1.27$ to 1.54$))$. Other elements associated with meeting PA were presence of bus or transit stops to walk to and presence of movies, libraries or churches to walk to $(\mathrm{OR}=1.12(95 \% \mathrm{Cl} 1.03$ to 1.23) and $\mathrm{OR}=1.19$ (95\% $\mathrm{Cl} 1.08$ to 1.31$)$, respectively). Conclusions In this analysis, the characteristic most strongly associated with PA was presence of places to walk and relax. Identifying communities that may lack amenities such as this, like a park, may help direct community investment to enhance structures that encourage activity.

\section{INTRODUCTION}

Many Americans do not meet physical activity (PA) recommendations of 150 min per week of moderate to vigorous PA. ${ }^{12}$ Sedentary lifestyle is associated with a myriad of health problems, including obesity, cardiovascular disease, diabetes and osteoarthritis. ${ }^{3-6}$ Increasingly, the built environment, such as access to sidewalks, crime rates and public transit, has been identified as contributors to meeting PA recommendations. ${ }^{7}$ A measure of built environment that contributes to PA is 'walkability'.

Walkability has been shown to be associated with likelihood of PA. ${ }^{8}$ When determined
Strengths and limitations of this study

This study includes a large, nationally representative sample of adults living in the USA

- This study contained high-quality data on physical activity.

- This study was limited by its cross-sectional nature.

- This study is limited as location and type of physical activity cannot be delineated by the standardised questions in the data set.

objectively, walkability is measured as street connectivity, land use mix, crime rates and population density through geospatial information systems techniques. ${ }^{9}$ For instance, greater presence of green spaces has been associated with increased PA. ${ }^{8}$ In one longitudinal study, walkable destinations, street connectivity and increased housing density were associated with greater gains in PA over time ${ }^{10}$ However, there is some evidence that perceived walkability may be more influential on activity than objectively measured elements. ${ }^{11}$ In particular, Jack and McCormack found that around $30 \%$ of their respondents who lived in objectively determined highly walkable areas felt their neighbourhood was not walkable.

Existing research on perceived environmental barriers to walking has been limited by relatively small sample sizes and restricted geographic areas, and existing studies may not generalise to the USA. ${ }^{7}$ In 2015 , the National Health Interview Survey (NHIS) introduced walkability questions. Research studies of these items have yet to link responses to walkability to meeting PA recommendations. ${ }^{12}$

To overcome limitations of existing research, particularly regarding small geographic areas and small sample sizes, we determined which elements of perceived 


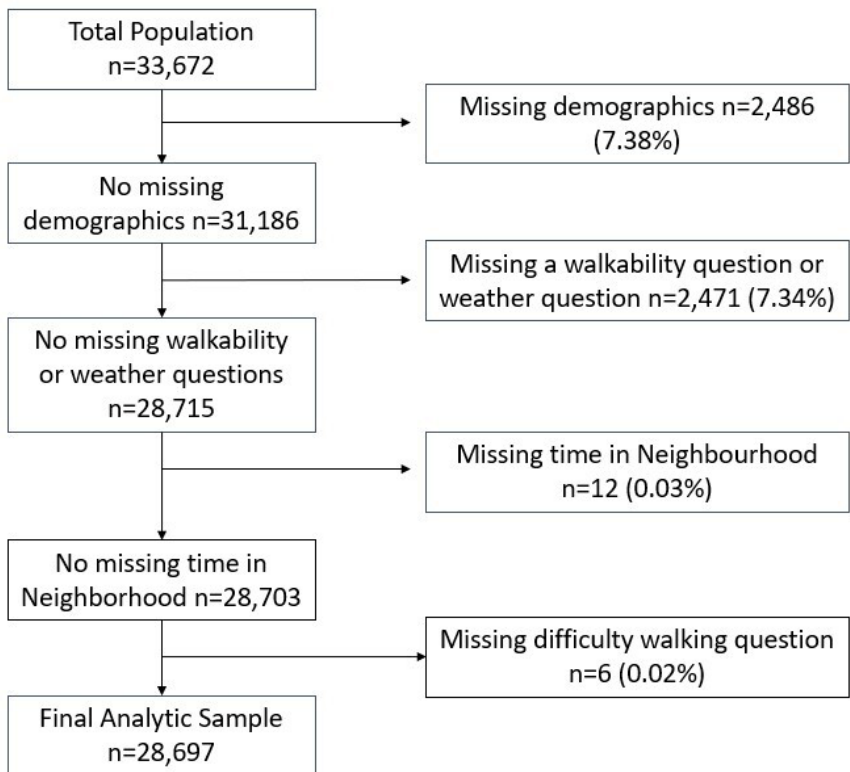

Figure 1 Flow of inclusion.

walkability are most highly associated with meeting PA recommendations in a large, nationally representative sample of US adults, collected from across the country.

\section{METHODS}

\section{Study population}

This cross-sectional study used self-reported data from the 2015 NHIS, which are collected through an in-person survey by trained representatives from the US Census Bureau. The NHIS is an annual population-based survey of the civilian, non-institutionalised US population used to monitor disease prevalence and disability as well as track progress towards goals stated by the Department of Health and Human Services. The NHIS uses multistage sampling techniques to partition the population into several nested levels of strata and clusters. ${ }^{13}$ After applying sampling weights, the sample is representative of the US non-institutionalised population. The annual response rate for 2015 was $70.1 \%$ of eligible households. ${ }^{13}$ Eligible participants for this analysis were at least 18 years old, had no missing data on walkability questions, PA outcomes and demographic data $(\mathrm{n}=28697)$. Complete case analysis was undertaken to minimise bias. See figure 1 for flow of inclusion.

\section{Exposures of interest-perceiving walkability and safety barriers to walking}

Perceived walkability and safety barriers were ascertained from nine questions pertaining to the participants' feelings about their neighbourhood. These questions centred on destinations to which participants could walk, as well as amenities to allow for walking and safety, specifically asking about walking (see Box 1). These questions were answered as either 'yes' or 'no', with safety questions reverse-coded for negative answers as ' 1 ' and positive answers at ' 0 '. Coding for walkability questions ensured

\section{Box 1 Content of questions for walkability and safety}

Walkability 'Where you live...'

are there roads, sidewalks, paths or trails where you can walk?'

'. . are there shops, stores, or markets that you can walk to?'

are there bus or transit stops that you can walk to?'

are there places like movies, libraries, or churches that you can walk to?

are there places that you can walk to that help you relax, clear your mind, and reduce stress?'

'... do most streets have sidewalks?'

Safety 'Where you live...'

'Does crime make it unsafe for you to walk?'

'Does traffic make it unsafe to walk?'

'Do dogs or other animals make it unsafe to walk?'

that perceptions of higher walkability were coded positively (ie, as ' 1 ').

\section{Outcome of interest}

Meeting PA recommendations was evaluated via a series of questions regarding participants' activity. Questions used to measure PA are shown in online supplemental Appendix A. The duration spent in each level of activity was summed to measure amount of PA per week. No data are available on the means by which the participant is active.

The sum was then converted into a bivariate variable of either meeting PA recommendations or not. Participants were categorised as meeting PA recommendations if they had greater than or equal to $150 \mathrm{~min}$ of $\mathrm{PA} /$ week and as not meeting if they had less than $150 \mathrm{~min}$. The questions in the NHIS data reliably measure PA. ${ }^{14}$

\section{Covariates}

All covariates were previously found to be associated with the likelihood of meeting PA recommendations. ${ }^{15-21}$ Covariates were self-reported and included gender, age (18-44 years, $45-64$ years and 65 plus years), race/ ethnicity (non-Hispanic white, non-Hispanic black, Hispanic/Latino or other), household highest educational attainment (Shigh school diploma/General Educational Development (GED), > high school to bachelors and postbachelor advanced degree), household incometo-poverty threshold ratio $(<1.00,1.00-1.99,2.00-2.99$, $3.00-3.99$ and $\geq 4.00$ ), marital status (never married, widowed/separated/divorced and married/living with partner), difficulty walking, social cohesion, psychological distress measured through the K6, weather as a barrier to walking and length of time living in the neighbourhood. Difficulty walking was assessed via a single question regarding how difficult the participant finds it to walk a quarter of a mile (rougly 402 metres) without an assistive device (not at all, only a little, somewhat, very, can't do or do not do this activity). Perceived social cohesion was based on four questions regarding the social nature of the neighbourhood. These questions were answered on a Likert scale ranging from 'strongly agree' (1) to 'strongly 
disagree' (4). Answers were tallied up with a maximum score of 16 (low social cohesion) and minimum score of four (high social cohesion). These totals were then categorised at a median split within the entire participant population to low and high social cohesion. The use of these questions in this manner was previously described by $\mathrm{Yi}$ et al in a national sample of NHIS participants. ${ }^{22}$ Internal consistency was assessed via Cronbach's alpha. A value of 0.893 was determined, supporting high internal validity. Psychological distress was measured via the K6 instrument, a validated questionnaire composed of six questions regarding psychological symptoms in the 30 days previous to administration. The K6 was categorised as low or high based on established cut-offs. ${ }^{23}$ A single question asked how frequently weather served as a barrier to walking. The answers were categorised as never, a little or some of the time and most or all of the time. Length of residence in the neighbourhood was included in the statistical models as this may affect the knowledge a participant has about their neighbourhood or the opportunity to interact with neighbours. Length of time was categorised as less than 1 year, 1-3 years, $4-10$ years, $11-20$ years and greater than 20 years.

\section{Patient and public involvement}

There was no patient or public involvement in the development or design of the study.

\section{Analysis}

All analyses take into account the complex sampling scheme by accounting for clustering, stratification and final sampling weight. Analysis of the included subpopulation used a domain statement to preserve integrity of the weights. ${ }^{24}$ No cases were eliminated from the sample. Analyses were coded with SAS V.9.4 using an alpha of 0.05.

Overall observed frequencies and weighted prevalence estimates for walkability, PA and covariates were calculated. Bivariate analyses using $\chi^{2}$ tests assessed the association of each covariate as well as each walkability question with meeting PA recommendations. Additionally, for each walkability question, standardised mean difference (SMD) was used as an effect size measure. SMD is a measure of distance or imbalance between two group means or prevalence estimates. ${ }^{25}$ For walkability questions, an SMD of greater than 10 was used as the criterion for inclusion in the adjusted logistic regression model. ${ }^{26}$ SMD was used as the large sample size of the NHIS dataset can identify differences that are small but not meaningful. Measuring the effect size in this manner allows for more meaningful identification of variables in this situation. Its use in this manner for bivariate data is described by Austin. ${ }^{27}$ To assess for any relationships and/ or multicollinearity among walkability questions, variance inflation factor and diagnostics were run with Variance Inflation Factor (VIF) $>10$ indicating multicollinearity. ${ }^{28}$ A fully adjusted logistic regression model included each walkability question with SMD $>10$ and all covariates to calculate ORs and $95 \%$ CIs.

\section{RESULTS}

\section{Demographics}

The final unweighted analytic sample included 28697 participants. The average age was 49.6 years $(\mathrm{SD}=18.3)$. The study population was $51.3 \%$ female and $66.1 \%$ nonHispanic white. Among this study population, 48.9\% ( $\mathrm{n}=13526,95 \%$ CI 48.0 to 49.7$)$ met PA recommendations.

\section{Univariate analysis of demographics and covariates with activity}

$\chi^{2}$ analysis revealed that age, sex, race/ethnicity, level of education, marital status, ratio of household income to poverty threshold, perceived social cohesion, K6 psychological distress measure, weather and time in neighbourhood were all significantly associated with whether participants met PA recommendations (all p<0.0001) (table 1).

\section{Univariate analysis aspects of neighbourhood and activity}

$\chi^{2}$ analysis found that all aspects of perceived neighbourhood conditions were associated with PA $(\mathrm{p}<0.0001)$. SMD analysis (table 2) found that places to walk or relax was associated with the largest SMD of 31.8, while presence of sidewalks on streets was associated with the smallest SMD of 9.43. As such, presence of sidewalks on streets was not included in the adjusted model. Multicollinearity assessment found no multicollinearity was present between any of the walkability variables (VIF $<2.00$ for all variables).

\section{Multivariate analysis}

Unadjusted and adjusted associations between each neighbourhood element and meeting PA recommendations are shown in table 3 . Model 1 indicated that places to walk and relax, presence of roads, sidewalks, paths or trail to walk, presence of bus or transit stops and presence of movie theatres, libraries or churches were all positively associated with meeting PA recommendations, while presence of sidewalks on streets was inversely associated with meeting PA recommendations (all $\mathrm{p}<0.01$ ). Lack of crime was also positively associated with meeting PA recommendations (OR=1.46 (95\% CI 1.30 to 1.64)). After adjusting for covariates, reporting a presence versus absence of places to walk to relax was associated with $40 \%$ increased odds of meeting PA recommendations $(\mathrm{OR}=1.40(95 \%$ CI 1.27 to 1.54$)$ ). Similarly, the presence versus absence of bus or transit stops to walk to, and movie theatres, libraries or churches to walk to, remained positively associated with meeting PA recommendations $(\mathrm{OR}=1.12$ (95\% CI 1.03 to 1.23 ) and $\mathrm{OR}=1.19$ (95\% CI 1.08 to 1.31 ), respectively). Low neighbourhood social cohesion was negatively associated with meeting PA recommendations $(\mathrm{OR}=0.85$ (95\% CI 0.78 to 0.92$)$ ).

\section{DISCUSSION}

In this cross-sectional study examining what neighbourhood aspects of walkability most influenced meeting PA recommendations, presence of places to walk and relax 
Table 1 Descriptive analysis of included population and univariate associations with physical activity, $\mathrm{n}=$ unweighted $\%=$ weighted

\begin{tabular}{|c|c|c|c|c|}
\hline Variable & $\begin{array}{l}\text { Overall } \\
\mathrm{n}=\mathbf{2 8 6 9 7}(\%)\end{array}$ & $\begin{array}{l}\text { Meeting physical } \\
\text { activity } \\
\text { n=13526 (\%) }\end{array}$ & $\begin{array}{l}\text { Not meeting } \\
\text { physical activity } \\
\mathrm{n}=15171(\%)\end{array}$ & $P$ value \\
\hline Age (years) & & & & $<0.0001$ \\
\hline $18-44$ & $12099(47.1)$ & $6779(54.3)$ & $5320(40.4)$ & \\
\hline $45-64$ & $9652(34.4)$ & $4302(31.8)$ & $5350(36.8)$ & \\
\hline $65+$ & $6946(18.4)$ & 2445 (13.9) & $4501(22.8)$ & \\
\hline Sex & & & & $<0.0001$ \\
\hline Female & $15750(51.3)$ & $6897(48.0)$ & $8853(54.5)$ & \\
\hline Male & $12947(48.7)$ & $6629(52.0)$ & $6318(45.5)$ & \\
\hline Race/ethnicity & & & & $<0.0001$ \\
\hline Non-Hispanic white & $18148(66.2)$ & $9043(68.7)$ & $9105(63.8)$ & \\
\hline Non-Hispanic black & $3834(11.9)$ & $1513(10.3)$ & $2321(13.4)$ & \\
\hline Other & $1866(6.2)$ & $939(6.6)$ & $927(5.8)$ & \\
\hline Hispanic & $4849(15.7)$ & $2031(14.4)$ & $2818(17.0)$ & \\
\hline Level of education & & & & $<0.0001$ \\
\hline High School diploma/GED or less & $8626(25.0)$ & $2786(17.1)$ & $5840(32.6)$ & \\
\hline Some college-associates/bachelors & $15466(56.3)$ & 7777 (58.5) & $7689(54.3)$ & \\
\hline Masters, professional, doctoral & $4605(18.7)$ & $2963(24.4)$ & $1642(13.1)$ & \\
\hline Marital status & & & & $<0.0001$ \\
\hline Married/living with partner & $14432(60.5)$ & $7064(61.5)$ & $7368(59.4)$ & \\
\hline Widowed/divorced/separated & $7646(17.4)$ & $2896(13.5)$ & $4750(21.1)$ & \\
\hline Never married & $6619(22.1)$ & $3566(25.0)$ & $3053(19.5)$ & \\
\hline Ratio household income to poverty threshold & & & & $<0.0001$ \\
\hline$<1.00$ & $4596(12.4)$ & $1632(9.8)$ & $2964(14.9)$ & \\
\hline $1.00-1.99$ & $6034(18.7)$ & $2199(14.1)$ & $3835(23.1)$ & \\
\hline 2.00-3.99 & $8266(28.8)$ & $3854(27.2)$ & $4412(30.2)$ & \\
\hline 4.00 or more & $9801(40.1)$ & $5841(48.9)$ & $3960(31.8)$ & \\
\hline Difficulty walking $1 / 4$ mile & & & & $<0.0001$ \\
\hline Not at all difficult & $22371(81.3)$ & $12384(92.9)$ & $9987(70.3)$ & \\
\hline Only a little difficult & $1587(5.0)$ & $486(3.1)$ & $1101(6.8)$ & \\
\hline Somewhat difficult & $1402(4.3)$ & $313(2.1)$ & $1089(6.4)$ & \\
\hline Very difficult & $1068(3.1)$ & $142(0.7)$ & $926(5.3)$ & \\
\hline Can’t do at all & $1561(4.2)$ & $130(0.7)$ & $1431(7.6)$ & \\
\hline Do not do this activity & $708(2.1)$ & $71(0.5)$ & $637(3.6)$ & \\
\hline Social cohesion & & & & $<0.0001$ \\
\hline Low & $9855(33.7)$ & $4262(30.4)$ & $5593(36.9)$ & \\
\hline High & $18842(66.3)$ & $9264(69.6)$ & $9578(63.1)$ & \\
\hline K6 psychological distress & & & & $<0.0001$ \\
\hline Distressed & $1654(5.6)$ & $470(3.4)$ & $1184(7.6)$ & \\
\hline No distress & $27043(94.4)$ & $13056(96.6)$ & $13987(92.4)$ & \\
\hline Weather as a barrier & & & & $<0.0001$ \\
\hline All or most of the time & $10049(34.1)$ & $3921(28.7)$ & $6128(39.3)$ & \\
\hline Some or a little of the time & 11705 (41.5) & $6575(48.6)$ & $5130(34.8)$ & \\
\hline
\end{tabular}

Continued 


\begin{tabular}{lcccc}
\hline Variable & $\begin{array}{l}\text { Overall } \\
\mathbf{n}=\mathbf{2 8 6 9 7}(\%)\end{array}$ & $\begin{array}{l}\text { Meeting physical } \\
\text { activity } \\
\mathbf{n = 1 3 5 2 6}(\%)\end{array}$ & $\begin{array}{l}\text { Not meeting } \\
\text { physical activity } \\
\mathbf{n = 1 5 1 7 1}(\%)\end{array}$ & P value \\
\hline Never & $6943(24.4)$ & $3030(22.7)$ & $3913(25.9)$ & $<0.0001$ \\
\hline Time in neighbourhood (years) & & & & \\
$<1$ & $3940(12.9)$ & $2047(13.8)$ & $1893(12.0)$ & \\
$1-3$ & $6007(20.6)$ & $3077(22.0)$ & $2930(19.2)$ \\
$4-10$ & $7471(26.5)$ & $3608(27.3)$ & $3863(25.8)$ \\
$11-20$ & $4961(19.4)$ & $2314(19.3)$ & $2647(19.5)$ \\
$>20$ & $6318(20.6)$ & $2480(17.6)$ & $3838(23.5)$ \\
\hline
\end{tabular}

GED, General Educational Development.

was most strongly associated with meeting PA recommendations. Presence of amenities and destinations were also positively associated with meeting PA recommendations. The strength of association between places to walk and relax may reflect general preferences for walking for leisure as opposed to transport. These two types of activity appear to be differentially associated with certain neighbourhood characteristics. ${ }^{29}$ For example, WalkScore is more strongly associated with Active Transport, rather than leisure walking. ${ }^{30}$ This study elucidates influential aspects of an individual's neighbourhood on PA. Evidence suggests advice to increase PA from a clinician may be associated with increased activity. ${ }^{31}$ However, clinicians should be sensitive to the socioecological factors that influence activity, including aspects of neighbourhood environment. ${ }^{32}$ Clinicians who identify specific amenities for their patients may have more success in counselling their patients to increase their activity.

This study's findings are consistent with a growing body of evidence that environmental attributes are associated with PA. ${ }^{833}$ Addy $e t a l^{33}$ found that the presence of amenities was associated with increased PA. Smith et al similarly found that built environment is associated with increased active transport. ${ }^{8}$

This study has several strengths, including the large sample size, nationally representative nature, strong validity to social cohesion index and standardised methods for data collection. Its cross-sectional design and results do not support conclusions about causality. All data were self-reported data; however, evidence suggests that selfreported data on health and exercise are highly valid. ${ }^{14}$ The walkability questions used are relatively new to the NHIS and have not been compared with any other perceived walkability scale, such as the Neighbourhood Environment Walkability Scale, possibly limiting validity, though in our previous published work, an index constructed from these questions demonstrated high internal validity. ${ }^{34}$ Furthermore, meeting PA recommendations does not necessarily mean that the PA occurs in the neighbourhood. Additionally, residential self-selection, for example, individuals who are 'walkers' are more likely to choose to live in a walkable place, has been associated with walking in one's neighbourhood. ${ }^{9}$ These data do not offer any ability to adjust for this potential bias.

Table 2 Univariate associations between walking promoting neighbourhood built environment, safety perception and meeting physical activity recommendations using standardised mean difference (SMD)

\begin{tabular}{|c|c|c|c|c|c|}
\hline Variable & $\begin{array}{l}\text { Overall } \\
\mathrm{n}=28697(\%)\end{array}$ & $\begin{array}{l}\text { Meeting physical } \\
\text { activity } \\
n=13526(\%)\end{array}$ & $\begin{array}{l}\text { Not meeting } \\
\text { physical activity } \\
\mathrm{n}=15171(\%)\end{array}$ & $\chi^{2}$ P value & SMD \\
\hline Roads, Sidewalks, paths or trails to walk & $24579(85.0)$ & 12052 (88.2) & $12527(82.1)$ & $<0.0001$ & 17.2 \\
\hline Shops, stores and markets to walk to & $17247(58.1)$ & 8675 (61.9) & $8572(54.4)$ & $<0.0001$ & 15.3 \\
\hline Movies, libraries or churches & $14359(47.6)$ & $7413(52.4)$ & $6946(42.9)$ & $<0.0001$ & 19.1 \\
\hline Crime does not make it unsafe & $24723(87.6)$ & $12009(90.0)$ & $12714(85.4)$ & $<0.0001$ & 13.9 \\
\hline Animals do not make it unsafe & 25409 (89.4) & $12190(91.0)$ & $13219(87.8)$ & $<0.0001$ & 10.5 \\
\hline Traffic does not make it unsafe to walk & $21816(76.5)$ & $10633(78.9)$ & $11183(74.2)$ & $<0.0001$ & 11.1 \\
\hline
\end{tabular}

$\mathrm{n}=$ unweighted \%=weighted. 
Table 3 Unadjusted and adjusted binomial logistic regression for odds of meeting physical activity recommendations

\begin{tabular}{|c|c|c|c|c|c|c|}
\hline \multirow[b]{2}{*}{ Variables } & \multicolumn{3}{|c|}{ Model 1} & \multicolumn{3}{|l|}{ Model 2} \\
\hline & OR & $95 \% \mathrm{Cl}$ & $P$ value & OR & $95 \% \mathrm{Cl}$ & $P$ value \\
\hline \multicolumn{7}{|l|}{ Neighbourhood questions } \\
\hline Places to walk to relax & 1.76 & 1.62 to 1.93 & $<0.0001$ & 1.40 & 1.27 to 1.54 & $<0.0001$ \\
\hline Roads, SW, paths or trails to walk & 1.25 & 1.12 to 1.41 & 0.0001 & 1.09 & 0.97 to 1.22 & 0.1401 \\
\hline Shops, stores, markets to walk to & 0.99 & 0.90 to 1.09 & 0.8601 & 0.95 & 0.85 to 1.06 & 0.3607 \\
\hline Do streets have sidewalks & 0.86 & 0.78 to 0.94 & 0.0019 & & & \\
\hline Bus or transit stops to walk to & 1.16 & 1.07 to 1.27 & 0.0006 & 1.12 & 1.03 to 1.23 & 0.0132 \\
\hline Movies, libraries or churches & 1.20 & 1.10 to 1.31 & $<0.0001$ & 1.19 & 1.08 to 1.31 & 0.0004 \\
\hline Crime does not make it unsafe & 1.46 & 1.30 to 1.64 & $<0.0001$ & 1.09 & 0.95 to 1.24 & 0.2145 \\
\hline Animals do not make it unsafe & 1.12 & 0.99 to 1.28 & 0.0722 & 0.97 & 0.84 to 1.11 & 0.6212 \\
\hline Traffic does not make it unsafe to walk & 1.04 & 0.94 to 1.14 & 0.4569 & 0.94 & 0.85 to 1.03 & 0.1745 \\
\hline Age (years) & & & & & & $<0.0001$ \\
\hline $18-44$ & & & & 1.00 (ref) & & \\
\hline $45-64$ & & & & 0.76 & 0.70 to 0.83 & \\
\hline $65+$ & & & & 0.80 & 0.72 to 0.90 & \\
\hline Sex & & & & & & $<0.0001$ \\
\hline Female & & & & 0.86 & 0.80 to 0.92 & \\
\hline Male & & & & 1.00 (ref) & & \\
\hline Race/ethnicity & & & & & & $<0.0001$ \\
\hline Non-Hispanic white & & & & 1.00 (ref) & & \\
\hline Non-Hispanic black & & & & 0.80 & 0.72 to 0.89 & \\
\hline Other & & & & 0.85 & 0.72 to 1.00 & \\
\hline Hispanic/Latino & & & & 0.83 & 0.75 to 0.93 & \\
\hline Level of education & & & & & & $<0.0001$ \\
\hline HS diploma/GED or less & & & & 0.47 & 0.42 to 0.54 & \\
\hline Some college-Associates/bachelors & & & & 0.71 & 0.65 to 0.79 & \\
\hline Masters, professional and doctoral & & & & 1.00 (ref) & & \\
\hline Marital status & & & & & & 0.0005 \\
\hline Married/living with partner & & & & 1.00 (ref) & & \\
\hline Widowed/divorced/separated & & & & 1.10 & 1.00 to 1.21 & \\
\hline Never married & & & & 1.24 & 1.11 to 1.39 & \\
\hline Ratio household income to poverty threshold & & & & & & $<0.0001$ \\
\hline$<1.00$ & & & & 0.66 & 0.58 to 0.74 & \\
\hline $1.00-1.99$ & & & & 0.61 & 0.54 to 0.68 & \\
\hline 2.00-3.99 & & & & 0.76 & 0.69 to 0.83 & \\
\hline 4.00 or more & & & & 1.00 (ref) & & \\
\hline Difficulty walking $1 / 4$ mile & & & & & & $<0.0001$ \\
\hline Not at all difficult & & & & 1.00 (ref) & & \\
\hline Only a little difficult & & & & 0.45 & 0.38 to 0.54 & \\
\hline Somewhat difficult & & & & 0.34 & 0.28 to 0.41 & \\
\hline Very difficult & & & & 0.15 & 0.12 to 0.20 & \\
\hline Can't do at all & & & & 0.11 & 0.08 to 0.14 & \\
\hline Do not do this activity & & & & 0.18 & 0.13 to 0.26 & \\
\hline Social cohesion & & & & & & $<0.0001$ \\
\hline Low & & & & 0.85 & 0.78 to 0.92 & \\
\hline
\end{tabular}


Table 3 Continued

\begin{tabular}{|c|c|c|c|c|c|c|}
\hline \multirow[b]{2}{*}{ Variables } & \multicolumn{3}{|c|}{ Model 1} & \multicolumn{3}{|l|}{ Model 2} \\
\hline & OR & $95 \% \mathrm{Cl}$ & $P$ value & OR & $95 \% \mathrm{Cl}$ & $P$ value \\
\hline High & & & & 1.00 (ref) & & \\
\hline Distressed & & & & 0.81 & 0.68 to 0.98 & \\
\hline No distress & & & & 1.00 (ref) & & \\
\hline All or most of the time & & & & 0.84 & 0.77 to 0.92 & \\
\hline Some or a little of the time & & & & 1.28 & 1.17 to 1.40 & \\
\hline Never & & & & 1.00 (ref) & & \\
\hline Time in neighbourhood (years) & & & & & & 0.2896 \\
\hline$<1$ & & & & 1.10 & 0.96 to 1.26 & \\
\hline $11-20$ & & & & 1.03 & 0.91 to 1.16 & \\
\hline$>20$ & & & & 1.00 (ref) & & \\
\hline
\end{tabular}

\section{CONCLUSIONS}

In this nationally representative study of adults, places to relax and the presence of amenities and destinations were associated with increase odds of meeting PA recommendations. Though certain factors may influence activity in a general population, further studies may investigate whether particular populations are influenced differentially. Some disease states, such as arthritis or cardiovascular disease, may favour different amenities compared with an unaffected population. ${ }^{35}$ For example, Timmermans $e t a l^{35}$ found that retail outlets were more associated with PA among older adults with osteoarthritis compared with a general population. Various age demographics may also benefit from different amenities. One such study demonstrated that older adults tend to be more connected to their neighbourhood amenities than younger adults. ${ }^{36}$ Further studies measuring walking behaviour may help understand which elements are most closely connected to measured activity to allow for informed neighbourhood design and policy change around urban planning.

Contributors SCG, LFC and JoS designed the study. SCG and JoS analysed and interpreted the data. SG, JoS and JeS wrote the article. All authors made critical revision to the article. All authors have read and approved the final version of the manuscript.

Funding The authors have not declared a specific grant for this research from any funding agency in the public, commercial or not-for-profit sectors.

Competing interests None declared.

Patient consent for publication Not required.

Provenance and peer review Not commissioned; externally peer reviewed.

Data availability statement Data are available in a public, open access repository. The National Health Interview Survey Data are publicly available at the following URL https://www.cdc.gov/nchs/nhis/nhis_2015_data_release.htm. Statistical code is available on reasonable request.

Open access This is an open access article distributed in accordance with the Creative Commons Attribution Non Commercial (CC BY-NC 4.0) license, which permits others to distribute, remix, adapt, build upon this work non-commercially, and license their derivative works on different terms, provided the original work is properly cited, appropriate credit is given, any changes made indicated, and the use is non-commercial. See: http://creativecommons.org/licenses/by-nc/4.0/.

ORCID iD

Sarah C Gebauer http://orcid.org/0000-0003-3790-6490

\section{REFERENCES}

1 Hootman JM, Macera CA, Ham SA, et al. Physical activity levels among the general US adult population and in adults with and without arthritis. Arthritis Rheum 2003;49:129-35.

2 Centers for disease control and prevention current physical activity guidelines.updated 11/29/2016. Available: https://www.cdc.gov/ cancer/dcpc/prevention/policies_practices/physical_activity/ guidelines.htm [Accessed 4 Oct 2018].

3 Balhareth A, Meertens R, Kremers S, et al. Overweight and obesity among adults in the Gulf states: a systematic literature review of correlates of weight, weight-related behaviours, and interventions. Obes Rev 2019;20:763-93.

4 Kaminsky LA, Arena R, Ellingsen O, et al. Cardiorespiratory fitness and cardiovascular disease - The past, present, and future. Prog Cardiovasc Dis 2019;62:86-93.

5 Aune D, Norat T, Leitzmann M, et al. Physical activity and the risk of type 2 diabetes: a systematic review and dose-response metaanalysis. Eur J Epidemiol 2015;30:529-42.

6 Semanik PA, Chang RW, Dunlop DD. Aerobic activity in prevention and symptom control of osteoarthritis. Pm R 2012;4:S37-44.

7 Hajna S, Ross NA, Brazeau A-S, et al. Associations between neighbourhood walkability and daily steps in adults: a systematic review and meta-analysis. BMC Public Health 2015;15:768.

8 Smith M, Hosking J, Woodward A, et al. Systematic literature review of built environment effects on physical activity and active transport - an update and new findings on health equity. Int $J$ Behav Nutr Phys Act 2017; $14: 158$.

9 McCormack GR, Shiell A. In search of causality: a systematic review of the relationship between the built environment and physical activity among adults. Int J Behav Nutr Phys Act 2011;8:125.

10 Hirsch JA, Moore KA, Clarke PJ, et al. Changes in the built environment and changes in the amount of walking over time: longitudinal results from the multi-ethnic study of atherosclerosis. Am $J$ Epidemiol 2014;180:799-809.

11 Jack E, McCormack GR. The associations between objectivelydetermined and self-reported urban form characteristics and neighborhood-based walking in adults. Int $\mathrm{J}$ Behav Nutr Phys Act 2014;11:71. 
12 Whitfield GP, Carlson SA, Ussery EN, et al. Environmental supports for physical activity, National health interview Survey-2015. Am J Prev Med 2018;54:294-8.

13 CDC. About the National health interview survey, 2016. Available: https://www.cdc.gov/nchs/nhis/about_nhis.htm2017

14 Sun F, Norman IJ, While AE. Physical activity in older people: a systematic review. BMC Public Health 2013;13:449.

15 Fontaine KR, Heo M, Bathon J. Are us adults with arthritis meeting public health recommendations for physical activity? Arthritis Rheum 2004;50:624-8.

16 Villanueva K, Knuiman M, Nathan A, et al. The impact of neighborhood walkability on walking: does it differ across adult life stage and does neighborhood buffer size matter? Health Place 2014;25:43-6.

17 Becerra MB, Bhattacharya Becerra M, Herring P, et al. Social determinants of physical activity among adult Asian-Americans: results from a population-based survey in California. J Immigr Minor Health 2015;17:1061-9.

18 Gidlow C, Johnston LH, Crone D, et al. A systematic review of the relationship between socio-economic position and physical activity. Health Educ J 2006;65:338-67.

19 Pratt M, Yin S, Soler R, et al. Does perceived neighborhood walkability and safety mediate the association between education and meeting physical activity guidelines? Prev Chronic Dis 2015;12:E46.

20 Wilcox S, Der Ananian C, Abbott J, et al. Perceived exercise barriers, enablers, and benefits among exercising and nonexercising adults with arthritis: results from a qualitative study. Arthritis Rheum 2006;55:616-27.

21 Shih M, Hootman JM, Kruger J, et al. Physical activity in men and women with arthritis National health interview survey, 2002. Am J Prev Med 2006;30:385-93.

22 Yi SS, Trinh-Shevrin C, Yen IH, et al. Racial/Ethnic differences in associations between neighborhood social cohesion and meeting physical activity guidelines, United States, 2013-2014. Prev Chronic Dis 2016;13:E165.

23 Kessler RC, Barker PR, Colpe LJ, et al. Screening for serious mental illness in the general population. Arch Gen Psychiatry 2003;60:184-9.
24 Lewis TH. Complex survey data analysis with SAS. Boca Raton: CRC Press, Taylor \& Francis Group, 2017.

25 Austin PC. An introduction to propensity score methods for reducing the effects of confounding in observational studies. Multivariate Behav Res 2011;46:399-424.

26 Austin PC, Stuart EA. Moving towards best practice when using inverse probability of treatment weighting (IPTW) using the propensity score to estimate causal treatment effects in observational studies. Stat Med 2015;34:3661-79.

27 Austin PC. Using the standardized difference to compare the prevalence of a binary variable between two groups in observational research. Commun Stat Simul Comput 2009;38:1228-34.

28 Kutner MH, Nachtsheim C, Neter J. Applied linear regression models. 4th ed. Boston; New York: McGraw-Hill/Irwin, 2004.

29 McCormack GR, Shiell A, Giles-Corti B, et al. The association between sidewalk length and walking for different purposes in established neighborhoods. Int J Behav Nutr Phys Act 2012;9:92.

30 Tuckel P, Milczarski W, Score W. Walk Score(TM), Perceived Neighborhood Walkability, and walking in the US. Am J Health Behav 2015;39:242-56.

31 Orrow G, Kinmonth A-L, Sanderson S, et al. Effectiveness of physical activity promotion based in primary care: systematic review and meta-analysis of randomised controlled trials. BMJ 2012;344:e1389.

32 AuYoung M, Linke SE, Pagoto S, et al. Integrating physical activity in primary care practice. Am J Med 2016;129:1022-9.

33 Addy CL, Wilson DK, Kirtland KA, et al. Associations of perceived social and physical environmental supports with physical activity and walking behavior. Am J Public Health 2004;94:440-3.

34 Gebauer S, Schootman M, Xian H, et al. Neighborhood built and social environment and meeting physical activity recommendations among mid to older adults with joint pain. Prev Med Rep 2020;18:101063.

35 Timmermans EJ, Schaap LA, Visser M, et al. The association of the neighbourhood built environment with objectively measured physical activity in older adults with and without lower limb osteoarthritis. BMC Public Health 2016;15:710.

36 Maisel JL. Impact of older adults' neighborhood perceptions on walking behavior. J Aging Phys Act 2016;24:247-55. 